UDC 347.734(4)

LBC 67.911.221.3,06

\title{
EVOLUTION OF BANKING SUPERVISION IN THE EUROPEAN UNION: ORGANIZATIONAL AND LEGAL ASPECTS
}

\author{
Elena B. Osokina \\ Moscow State Institute of International Relations (MGIMO University) \\ of the Interior Ministry of the Russian Federation, Moscow, Russian Federation
}

\begin{abstract}
Introduction: the article concentrates on the study of the problem of improving the system of legal regulation and supervision in the banking sector of the European Union. The methodological framework for the research is a set of general scientific methods of cognition, such as analysis, synthesis, system approach, and private law (formal and legal, comparative law) research methods. In the course of the conducted research the author has analyzed the main sources of international and European law, the studies of domestic and foreign scholars on the subject under discussion, the analytical documents of the international organizations and institutions of the European Union. Results: the results of the study have revealed that the consistent improvement of the supervisory mechanisms in the European Union was a response to increasing the integration processes in the financial markets. Conclusions: the banking system is a special system whose structural elements are in high interdependence, and the boundaries of this system go beyond the territorial jurisdiction of one state. Therefore, the national supervisory authorities cannot take any financial decisions in complete isolation and it is only the balanced distribution of powers between the supranational and national supervisory authorities that can ensure the stability and effective functioning of the financial system in the European Union. The progressive reform of banking regulation and banking supervision proved the effectiveness of this approach - the European Central Bank was given the authority to supervise the largest banks within the Single Supervisory Mechanism, the other banks are still under control of the national authorities. For working out a complex legal and regulatory framework of the EU financial sector and ensuring the uniform application of the worked out norms and rules at European Union level there was established a special body - the European Banking Authority.

Key words: European Banking Union, Single Supervisory Mechanism, European Central Bank, the Lamfalussy Process, The de Larosière Group's Report.
\end{abstract}

УДК 347.734(4)

ББК 67.911.221.3,06

\section{ЭВОЛЮЦИЯ БАНКОВСКОГО НАДЗОРА В ЕВРОПЕЙСКОМ СОЮЗЕ: ОРГАНИЗАЦИОННО-ПРАВОВЫЕ АСПЕКТЫ}

\section{Елена Борисовна Осокина}

Московский государственный институт международных отношений (университет)

Министерства иностранных дел Российской Федерации, г. Москва, Российская Федерация

Введение: статья посвящена исследованию проблем совершенствования системы правового регулирования и надзора в банковском секторе Европейского союза. Методологическую основу исследования 
составили общенаучные методы познания, такие как анализ, синтез, системный подход, и частноправовые (формально-юридический, сравнительно-правовой) методы. В рамках проведенного исследования проанализированы основные источники международного и европейского права, труды отечественных и зарубежных ученых по рассматриваемой тематике, аналитические документы международных организаций и институтов Европейского союза. Результаты: в ходе проведенного исследования выявлено, что последовательное совершенствование надзорных механизмов в Европейском союзе стало ответом на углубление интеграционных процессов на мировых финансовых рынках. Выводы: банковская система - это особая система, структурные элементы которой находятся в высокой взаимозависимости, а границы этой системы выходят за пределы территориальной юрисдикции одного государства. Именно поэтому национальные надзорные органы не могут принимать решения в финансовой сфере в полной изоляции, и только сбалансированное распределение полномочий между наднациональными и национальными надзорными органами может обеспечить устойчивость и эффективное функционирование финансовой системы в Европейском союзе. Поступательное реформирование банковского регулирования и банковского надзора доказало эффективность такого подхода - Европейский центральный банк получил полномочия по надзору за крупнейшими банками в рамках Единого надзорного механизма, остальные банки остались в ведении национальных регуляторов. Для разработки комплексного нормативно-правового регулирования финансового сектора ЕС и обеспечения единообразного применения разработанных норм и правил в рамках ЕС учрежден специальный орган Европейский банковский орган.

Ключевые слова: Европейский банковский союз, Единый надзорный механизм, Европейский центральный банк, процесс Ламфалусси, доклад группы Ларозьера.

\section{Введение}

В процессе завершения формирования единого рынка финансовых услуг в Европейском союзе возник вопрос об эффективности существующей модели банковского регулирования и банковского надзора на уровне ЕC, которая длительное время основывалась на автономии национальных органов и на системе сотрудничества и обмена информацией между ними. На протяжении последних десяти лет предлагалось множество вариантов углубления общеевропейского сотрудничества в этой сфере, и все они предполагали проведение дальнейшей гармонизации норм и правил и усовершенствование методов банковского надзора с целью повышения его эффективности. Однако европейские законодатели и национальные регуляторы длительное время не рассматривали возможность перераспределения полномочий посредством их передачи на наднациональный уровень.

Недостатки пруденциального регулирования и банковского надзора проявились в полной мере во время финансового и экономического кризиса 2008-2009 гг., который стал главной причиной проведения реформы правового регулирования и механизмов функционирования банковского сектора в ЕС и перехода на новый этап европейской интеграции посредством создания (в рамках Эко- номического и валютного союза) Европейского банковского союза.

Краткий обзор основных этапов эволюции организационно-правовой структуры регулирования и надзора в банковском секторе ЕС дает представление о масштабах реализуемого проекта.

\section{Первый этап: реформа механизмов регулирования (система Ламфалусси) и сотрудничества в сфере банковского надзора}

Реформа в финансовом секторе ЕС началась с упрощения и рационализации процедуры принятия решений. Разработанная процедура получила название «процесс Ламфалусси» (Lamfalussy Process), выражающийся в создании новой организационно-правовой структуры в сфере регулирования финансовых услуг [6]. Процесс Ламфалусси был представлен в 2001 г. как результат реализации мер, предусмотренных Планом действий в сфере финансовых услуг (Financial Services Action Plan) [7], основная цель которого заключалась в интеграции рынка финансовых услуг.

Первоначально новый механизм регулирования применялся только в отношении рынка ценных бумаг, но впоследствии было принято решение расширить его действие на банковский сектор и сферу страхования. Новая 


\section{МЕЖДУНАРОДНОЕ ПРАВО И СРАВНИТЕЛЬНОЕ ПРАВОВЕДЕНИЕ}

система регулирования предусматривала четыре уровня принятия решений:

1. На первом уровне Парламент и Совет ЕС принимают регламенты и директивы, которые содержат наиболее общие положения. Разработкой проектов нормативно-правовых актов занимается Европейская Комиссия.

2. На втором уровне разрабатываются нормативно-правовые акты, которые конкретизируют положения актов первого уровня. В рамках данного уровня законодательными полномочиями наделены надзорные органы, созданные в каждой сфере в отдельности: Европейский орган в области рынка ценных бумаг (European Securities and Markets Authority - ESMA) [4], Европейский банковский орган (European Banking Authority - EBA) [3], Европейский орган в области страхования и трудовых пенсий (EIOPA - European Insurance and Occupational Pensions Authority) [5]. Совет ЕС может принимать меры при возникновении разногласий между европейскими надзорными органами и Комиссией.

3. Третий уровень представлен техническими комитетами, в которые входят представители надзорных органов банковского сектора, рынка ценных бумаг и сферы страхования. Технические комитеты оказывают Комиссии консультативную помощь при разработке проектов актов первого и второго уровней и осуществляют координацию надзорных органов для обеспечения единообразной и последовательной имплементации актов первого и второго уровней. Они также следят за выполнением стандартов и способствуют гармонизации методов надзора.

4. В рамках четвертого уровня Европейская комиссия осуществляет проверку соблюдения государствами - членами ЕС принятых актов.

Процесс Ламфалусси как форма институционального развития был положительно воспринят, однако не обошлось и без критических замечаний в отношении каждого из уровней и их взаимодействия. Реформа регулирования финансового сектора не повлияла на распределение обязанностей по осуществлению банковского надзора, которые как и прежде оставались в компетенции национальных органов. Эффективность разработанной институциональной системы стремительно снижалась в условиях возрастающей интеграции на финансовых рынках.

\section{Второй этап: укрепление} межгосударственного сотрудничества

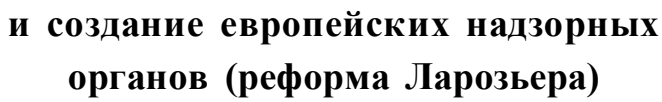

В момент наиболее острой фазы финансового и экономического кризиса 20082009 гг. стало очевидно, что действующая структура не подходит для урегулирования масштабных банковских кризисов. Обсуждения необходимости проведения реформы правового регулирования финансового сектора ЕС возобновились с новой силой. Европейские законодатели предлагали два направления ее проведения - гармонизация норм и изменение организационно-правовой структуры европейского надзора за финансовыми рынками. Проект реформы был разработан рабочей группой под председательством Жака де Ларозьера (с 1978-1987 - директора-распорядителя Международного валютного фонда, с 1987-1993 - председателя Банка Франции, 1993-1998 - председателя Европейского банка реконструкции и развития) [1] и изложен в специальном докладе группы от 25 февраля 2009 года [2]. Данный доклад определял новый подход к макропруденциальному и микропруденциальному надзору за банками, осуществляющими трансграничную деятельность.

В 2010 г. Европейский Парламент одобрил новое нормативно-правовое регулирование, которое учреждало Европейскую систему надзора за финансовыми рынками (European System of Financial Supervision/ESFS), включающую Европейский комитет по системным рискам (European System Risk Board/ESRB) и Европейские надзорные органы (European Supervisory Authority/EBA) [10].

Европейский комитет по системным рискам (далее - ЕКСР) отвечает за макропруденциальный надзор, который заключается в анализе рисков, предупреждении и экстренном реагировании. Главной задачей ЕКСР является определение областей, наиболее подверженных системным рискам, а именно «рискам возникновения нарушений в функционировании финансовой системы с возможностью наступления серьезных негативных последствий для внутреннего рынка и реальной экономики» (ст. 2 Регламента 1092/2010) [8]. 
Деятельность Европейских надзорных органов охватывает три сферы-банковскую, рынок ценных бумаг и страхование. Европейские надзорные органы работают совместно в рамках Объединенного комитета (Joint Committee), предусмотренного для целей укрепления сотрудничества и для обеспечения постоянного обмена информацией и согласования методов надзора. Основной задачей Объединенного комитета является обмен информацией с ЕКСР и укрепление сотрудничества между ЕКСР и Европейскими надзорными органами.

В рамках банковского сектора учрежден Европейский банковский орган, в структуру которого входят:

1. Совет наблюдателей, включающий представителей всех государств - членов ЕС (Board of Supervisors/BoS).

2. Комитет по финансовому оздоровлению банков (Resolution Committee/ResCo).

3. Правление (Management Board/MB) административный орган, ответственный за текущую деятельность Европейского банковского органа.

Европейский банковский орган выполняет большое количество функций, в которые входят:

1. Разработка комплексного нормативноправового регулирования финансового сектора (Единый свод правил оказания финансовых услуг (Single Rulebook for financial services)) и обеспечение его выполнения.

2. Обеспечение последовательного применения разработанных норм посредством издания руководств, предназначенных для национальных надзорных органов, с целью согласования методов надзора.

3. Усиление надзора за банковскими группами, осуществляющими трансграничную деятельность, при содействии Коллегии наблюдателей от каждого государства - члена ЕС.

4. Координация проведения стресс-тестов на европейском уровне для оценки устойчивости финансовых институтов к негативным тенденциям на финансовых рынках.

5. Обеспечение разработки согласованного плана действий национальных надзорных органов в кризисной ситуации.

6. Обеспечение прозрачности, удобства использования и доступности финансовых продуктов и услуг для потребителей.

\section{Третий этап: централизация} надзорных полномочий

\section{в финансовом секторе ЕС - создание Единого надзорного механизма}

Изменения институциональной структуры, предложенные в докладе де Ларозьера, стали важным этапом в развитии интеграции в сфере финансового регулирования и надзора ЕС. Однако они были лишь частью масштабной реформы, главной целью которой стало создание Единого надзорного механизма как одного из элементов Европейского банковского союза.

Единый надзорный механизм был введен Регламентом 1024/2013 15 октября 2013 года [9]. У чреждение Единого надзорного механизма ознаменовало переход от традиционных принципов сотрудничества и кооперации национальных органов к централизованной системе надзора в Еврозоне, которая основывалась на применении принципов субсидиарности и пропорциональности, закрепленных в ст. 5 Договора о ЕС. Государства - члены ЕС, не входящие в Еврозону, могут присоединиться к Единому надзорному механизму на добровольной основе посредством подписания соглашения о присоединении.

Единый надзорный механизм не обладает правосубъектностью. Полномочия по принятию решений возложены на Европейский центральный банк и национальные надзорные органы в соответствии с положениями Регламента 1024/2013 от 15 октября 2013 года. Европейский центральный банк осуществляет надзор за крупнейшими банками государств Еврозоны и присоединившихся к Единому надзорному механизму государств, в то время как национальные регуляторы осуществляют контроль за остальными банками. В рамках новой структуры издержки по реализации надзорных полномочий возложены на банки, входящие в Единый надзорный механизм.

Единый надзорный механизм - это не только перераспределение полномочий между европейскими и национальными надзорными органами. Он представляет собой новую систему совместной реализации надзорных полномочий, основанную на принципах европейской интеграции. Основная цель этой системы - разработка единообразных методов и высоких стандартов работы надзорных органов в ЕС. 


\section{МЕЖДУНАРОДНОЕ ПРАВО И СРАВНИТЕЛЬНОЕ ПРАВОВЕДЕНИЕ}

\section{Выводы}

Последние десятилетия в Европейском союзе наблюдалась тенденция расширения трансграничной деятельности финансовых посредников. Действующие механизмы банковского регулирования и банковского надзора в ЕС не успевали подстраиваться под стремительно меняющуюся действительность, и после финансового и экономического кризиса 2008-2009 гг. возникла необходимость в проведении масштабной реформы банковского сектора ЕС. Углубление интеграции на мировых финансовых рынках и интернационализация финансовых посредников заставили пересмотреть институциональную структуру банковского надзора и объем полномочий надзорных органов.

На основании вышесказанного можно сделать следующие выводы:

1. Недостатки пруденциального регулирования и банковского надзора проявились в полной мере во время мирового финансового и экономического кризиса 2008-2009 гг., который стал главной причиной проведения реформы правового регулирования банковского сектора в ЕC.

2. В результате проведенной реформы часть полномочий по надзору за банковским сектором передана на наднациональный уровень.

3. В 2010 г. Европейский Парламент одобрил новое нормативно-правовое регулирование, которое учреждало Европейскую систему надзора за финансовыми рынками (European System of Financial Supervision/ ESFS), включающую Европейский комитет по системным рискам (European System Risk Board/ESRB) и Европейские надзорные органы (European Supervisory Authority/EBA). Деятельность Европейских надзорных органов охватывает три сферы - банковскую, рынок ценных бумаг и страхование. В банковской сфере действует Европейский банковский орган, который занимается разработкой комплексного нормативно-правового регулирования финансового сектора ЕС и обеспечением единообразного применения разработанных норм и правил.

4. Единый надзорный механизм представляет собой новую систему совместной реализации надзорных полномочий, основанную на принципах европейской интеграции. В рамках Единого надзорного механизма Европейский центральный банк получил полномочия по надзору за крупнейшими банками Еврозоны и присоединившихся государств, остальные банки остались в ведении национальных регуляторов.

5. Единый надзорный механизм - первый этап перехода на новую ступень европейской интеграции - формирования Европейского банковского союза.

\section{СПИСОК ЛИТЕРАТУРЫ}

1. Аналитическое и информационное агентство Bloomberg : офиц. сайт. - Электрон. текстовые дан. - Режим доступа: http://www.bloomberg.com/ research/stocks/people/person. asp?personId $=794104$ \&privcapId=367964 (дата обращения: 10.04.2017). Загл. с экрана.

2. Доклад рабочей группы по финансовому надзору в ЕС. - Брюссель, 2009. - Электрон. текстовые дан. - Режим доступа: http://ec.europa.eu/ internal_market/finances/docs/de_larosiere_report_ en.pdf. -Загл. с экрана.

3. Европейский банковский орган : офиц. сайт. - Электрон. текстовые дан. - Режим доступа: http://www.eba.europa.eu/regulation-and-policy/ single-rulebook/interactive-single-rulebook (дата обращения: 05.04.2017). - Загл. с экрана.

4. Европейский орган в области рынка ценных бумаг : офиц. сайт. - Электрон. текстовые дан. Режим доступа: https://www.esma.europa.eu (дата обращения: 07.04.2017). - Загл. с экрана.

5. Европейский орган в области страхования и трудовых пенсий : офиц. сайт. - Электрон. текстовые дан. - Режим доступа: https://eiopa.europa.eu (дата обращения: 05.04.2017). - Загл. с экрана.

6. Касьянов, Р. А. Организация деятельности финансовых регуляторов в Европейском союзе / Р. А. Касьянов // Вестник МГИМО Университета. - 2012. - № 6. - С. 147-152.

7. План действий в сфере финансовых услуг 1999 г. // Европейская комиссия : офиц. сайт. - Электрон. текстовые дан. - Режим доступа: http://ec. europa.eu/internal_market/finances/docs/actionplan/ index/action en.pdf. - Загл. с экрана.

8. Регламент 1092/2010 Европейского Парламента и Совета ЕС от 24 нояб. 2010 г. об осуществлении макропруденциального надзора за финансовой системой ЕС и учреждении Европейского совета по системным рискам // Official Journal. 2010. - L331. - Dec. 15. - P. 1-11. 
9. Регламент Совета ЕС 1024/2013 от 15 окт. 2013 г. о предоставлении полномочий Европейскому центральному банку по определению политики в области пруденциального надзора за кредитными организациями // Official Journal. - 2013. L 287. - Oct. 29. - Р. 63-89. - Электрон. текстовые дан. - Режим доступа: http://eur-lex.europa.eu/legalcontent/EN/TXT/?uri=CELEX\%3A32013R1024. Загл. с экрана.

10. Топорнин, Н. Б. Некоторые аспекты правового статуса и деятельности механизмов финансовой помощи в Европейском союзе / Н. Б. Топорнин // Деньги и кредит. - 2015. - № 10. - С. 58-61.

\section{REFERENCES}

1. Analiticheskoe i informatsionnoe agentstvo Bloomberg: ofits. sayt [Bloomberg Analytical and Information Agency: Official Website]. URL: http:// www.bloomberg.com/research/stocks/people/person. asp?personId=794104\&privcapId=367964. (accessed April 10, 2017).

2. Doklad rabochey gruppy po finansovomu nadzoru $v$ ES [Report of the Working Group on Financial Supervision in the EU]. Brussels, 2009. URL: http://ec.europa.eu/internal_market/finances/docs/ de_larosiere_report_en.pdf.

3. Evropeyskiy bankovskiy organ: ofits. sayt [European Banking Authority: Official Website]. URL: http://www.eba.europa.eu/regulation-and-policy/ single-rulebook/interactive-single-rulebook. (accessed April 5, 2017).

4. Evropeyskiy organ v oblasti rynka tsennykh bumag: ofits. sayt. [European Authority in the Securities Market. Official Website]. URL: http:// www.eba.europa.eu. (accessed April 7, 2017).

5. Evropeyskiy organ v oblasti strakhovaniya i trudovykh pensiy : ofits. sayt [European Insurance and Occupational Pensions Authority. Official Website]. URL: https://eiopa.europa.eu. (accessed April 5, 2017).

6. Kasyanov R.A. Organizatsiya deyatelnosti finansovykh regulyatorov $\mathrm{v}$ Evropeyskom coyuze [Financial Regulators in the EU]. Vestnik MGIMO Universiteta, 2012, no. 6, pp. 147-152.

7. Plan deystviy v sfere finansovykh uslug 1999 g. [Action Plan in the Sphere of Financial Services in 1999]. Evropeyskaya komissiya: ofits. sayt [Official Website of the European Commission]. URL: http:// ec.europa.eu/internal_market/finances/docs/ actionplan/index/action_en.pdf.

8. Reglament 1092/2010 Evropeyskogo Parlamenta i Soveta ES ot 24 noyab. 2010 g. ob osushchestvlenii makroprudentsialnogo nadzora za finansovoy sistemoy ES i uchrezhdenii Evropeyskogo soveta po sistemnym riskam [Regulation no. 1092/2010 of the European Parliament and of the EU Council of November 24, 2010 on EU Macro-Prudential Oversight of the Financial System and Establishing a European Systemic Risk Boar]. Official Journal, 2010, L 331, pp. 1-11.

9. Reglament Soveta ES 1024/2013 ot 15 okt. 2013 g. o predostavlenii polnomochiy Evropeyskomu tsentralnomu banku po opredeleniyu politiki v oblasti prudentsialnogo nadzora za kreditnymi organizatsiyami [Regulation of EU Council no. 1024/2013 of October 15, 2013 on Conferring Specific Rights to the European Central Bank on the Policies Relating to the Prudential Supervision over Credit Institutions]. Official Journal, 2013, L 287, pp. 63-89. URL: http://eur-lex.europa.eu/ legal-content/EN/TXT/?uri=CELEX\%3A32013R1024.

10. Topornin N.B. Nekotorye aspekty pravovogo statusa i deyatelnosti mekhanizmov finansovoy pomoshchi v Evropeyskom soyuze [Some Aspects of Legal Status and Activities of Financial Assistance Mechanisms in the European Union]. Dengi i kredit, 2015, no. 10, pp. 58-61.

\section{Information about the Author}

Elena B. Osokina, Postgraduate Student, Department of European Law, Moscow State Institute of International Relations (MGIMO University) of the Interior Ministry of the Russian Federation, Prosp. Vernadskogo, 76, 119454 Moscow, Russian Federation, elenaosokina2016@yandex.ru.

\section{Информация об авторе}

Елена Борисовна Осокина, аспирант кафедры европейского права, Московский государственный институт международных отношений (университет) Министерства иностранных дел Российской Федерации, просп. Вернадского, 76, 119454 г. Москва, Российская Федерация, elenaosokina2016@yandex.ru. 